\title{
CONTRATRANSFERÊNCIA E COMPAIXÃO: ENCONTRO CLÍNICO COM UM RAPAZ HIV+
}

\author{
Vera Lúcia Mencarelli* \\ Tânia Maria José Aiello Vaisberg**
}

\section{RESUMO}

O trabalho traz a narrativa de um encontro entre uma psicanalista, membro de equipe multidisciplinar referenciada para o tratamento de moléstias infecciosas, DST(s) e AIDS, com um adolescente que acaba de ter conhecimento a respeito de sua condição de soropositividade para o HIV. A condição existencial do jovem, vivendo em situação social precária que reúne pobreza e vitimização de ação violenta, coloca a psicanalista em contato com intensos sentimentos contratransferenciais, objetos de reflexão na busca de articulação teórica segundo o referencial winnicottiano. $\mathrm{O}$ artigo aponta para a necessidade de se pensar sobre a experiência de compaixão na contratransferência, como fenômeno emergente em clínica extensa e diferenciada que leva o psicanalista ao encontro de dramáticas humanas marcadas por sofrimento intenso.

Palavras-chave: psicanálise winnicottiana, HIV/AIDS, sofrimento humano, compaixão, contratransferência

\section{AbSTRaCT}

COUNTERTRANSFERENCE AND COMPASSION: A CLINICAL ENCOUNTER WITH AN HIV+ YOUTH

The essay brings the narrative of an interview between a psychoanalysts, member of a multidisciplinary team indicated for the treatment of infectious diseases, STD's and AIDS,

* Mestre pelo Instituto de Psicologia da Universidade de São Paulo; Doutoranda pelo mesmo Instituto; Psicóloga do Ambulatório de Moléstias Infecciosas e Programa DST/aids de Santo André.

** Professora Livre Docente pelo Instituto de Psicologia da Universidade de São Paulo; Orientadora Colaboradora do Programa de Pós-graduação do Instituto de Psicologia da Universidade de São Paulo; Orientadora Permanente do Programa de Pós-graduação da Pontifícia Universidade Católica de Campinas. 
with an adolescent who has just been informed about his HIV-positive status. The youth's existential condition, living in a precarious social situation combined with poverty and victimization, puts the psychoanalyst in touch with intense countertransference feelings, which are reflected upon seeking theoretic articulation with a Winnicottian referential. The article shows a need to think about the experience of compassion in counter-transference, as a phenomenon which has a place in an extended and differentiated clinic that puts the psychoanalyst in touch with human dramas marked by intense suffering.

Keywords: Winnicott psychoanalysis, HIVIAIDS, human suffering, compassion, countertransference

O psicoterapeuta (analista ou psicólogo analista) deve permanecer vulnerável e ainda assim reter seu papel profissional durante suas horas de trabalho. Acho que o analista profissional que mantém comportamento correto está mais à vontade do que o analista que (ainda que com comportamento correto) retém a vulnerabilidade que faz parte de uma organização defensiva flexivel.

(Winnicott, [1960] 1983: 147)

Pretendemos neste texto apresentar o trabalho que uma de nós exerce, como psicóloga/psicanalista, em uma organização governamental ${ }^{1}$ dedicada ao tratamento de pessoas soropositivas para o HIV. Sua colocação como membro de uma equipe multiprofissional referenciada para o cuidado destes pacientes, bem como de seus familiares, tem nos inspirado investimentos de estudo e pesquisa a partir da emergência de questionamentos que esta clínica impõe. Como uma das formas de inserção neste trabalho, a psicanalista atua no acolhimento a pacientes novos ou usuários antigos e nesta situação confronta-se com infeliz quantidade e diversidade de sofrimento humano.

Parte destas interrogações acabou por instigar a elaboração de uma dissertação de mestrado (Mencarelli, 2003). Por um lado, o convívio da psicanalista com os pacientes e com a equipe e, por outro, a busca por uma adequação à demanda de seus pacientes levaram-na a aprofundar vínculos constituídos com as Oficinas Psicoterapêuticas Ser e Fazer do IPUSP, iniciativa fundada e coordenada pela outra de nós, co-autora deste artigo.

Neste espaço de estudo e pesquisa, fundamentamos teórica/metodologicamente a clínica da qual lançamos mão (Mencarelli \& Vaisberg, 2005). Forjamos um enquadramento clínico diferenciado a ser ofertado como atendimento psicoterapêutico para os pacientes que o solicitavam: a oficina de velas ornamentais. Este empreendimento foi precedido por algumas constatações, citadas a se- 
guir, que acabaram por suscitar a resposta mais pertinente para ir ao encontro do paciente sofredor.

Não parecia haver interesse por parte dos pacientes que procuravam ajuda psicológica de envolverem-se em um tipo de trabalho psicoterapêutico que, habitualmente, o psicanalista costuma exercer. Referimo-nos à adoção de uma forma tradicional de trabalhar na qual se visa a busca de determinantes lógico-emocionais inconscientes que justificam o sofrer e que, em sendo elucidados por intermédio de sentença interpretativa, trazem algum alívio para o sofrimento. Ainda que consideremos que todo sofrer tenha sentido imerso e presentificado na subjetividade de cada um, pudemos reconhecer que o núcleo do sofrer vinculava-se a algo que os acometia desde fora, não fazendo parte apenas de um mundo imaginário.

Mesmo para aqueles que se apresentavam com relativa estabilidade emocional, alguns até mesmo tendo encontrado na adversidade ocasião de ver suas potencialidades humanas fortalecidas, o diagnóstico e tratamento da infecção pelo HIV oferece grande potencial ${ }^{2}$ para a emergência de estados de angústias que podem atingir patamares de verdadeira agonia ${ }^{3}$. Pudemos isolar este como fenômeno clínico de base: a possibilidade de aproximação de experiências agônicas.

Por outro lado, havia e ainda há uma exigência, estendida a todos os profissionais desta equipe, para que, além da atuação em núcleo específico, atuem como educadores em saúde. Espera-se que qualquer profissional que trabalhe com moléstias infecto-contagiosas possa e deva, prontamente, orientar os pacientes com o objetivo de instrumentá-los no sentido da contenção da expansão epidemiológica das referidas doenças e, concomitantemente, manter, na medida das possibilidades, seu próprio bem-estar.

Diante de tudo isto surgia uma pergunta: como ser psicanalista neste contexto? A resposta elucidativa vinha com uma sugestão de Winnicott ([1962] 1983) em um texto muito apreciado por nós da Ser e Fazer, intitulado "Os objetivos do tratamento psicanalítico”. Diz o autor que quando o paciente precisa de análise faz-se análise. Em sendo prementes outras necessidades, faz-se outra coisa, constelando uma situação onde somos psicanalistas fazendo algo mais apropriado para a situação.

Nas oficinas psicoterapêuticas Ser e Fazer seguimos empreendendo o método psicanalítico, utilizando-o, no entanto, de maneira diversa da tradicional. Adotamos, reinterpretando-as ao nosso modo, indicações de Herrmann ([1979] 2001) que apontam que o emprego do método psicanalítico determina-se pela operação de ruptura de campos. O autor refere-se à ruptura de campos discursivos, ação que, disparada pelo psicanalista, lança o analisando para um 
"sem fim" de novas possibilidades de sentido contidas em seu "falar". Nas oficinas psicoterapêuticas o que se intenta é a ruptura, ou melhor, a transformação, como temos preferido nos referir, do campo das agonias impensáveis (Vaisberg, 2002) em angústias suportáveis.

Segundo nossa compreensão, a doença ou mesmo seu severo tratamento podem ser sentidos pelo paciente como fenômenos extremamente invasivos. Quando isto acontece, a integração do si mesmo pode ser ameaçada. Ronda a ameaça do não se sentir mais real, vivo e uno. É comum ouvirmos relatos de pacientes que reduzem seu ser à própria doença.

Convém que nos detenhamos em considerações a respeito de como apreendemos conceitualmente a integração. Muitos leitores apressados julgam que a noção winnicottiana de integração corresponde a uma visão pré-psicanalítica do homem, que a psicanálise descreveu como essencialmente descentrado. A integração é assim mal compreendida, como realização de um projeto impossível, de coincidência entre o sonho e a vida, o desejo e a realidade. Entretanto, não se trata disto. Winnicott chega ao conceito pela via do estudo do sofrimento esquizofrênico, no qual defesas primitivas constelam estados de desintegração pessoal, extremamente aflitivos. Não se nega obviamente que, enquanto sujeito psíquico, o homem seja inevitavelmente descentrado. Por outro lado, não se desconhece que é a experiência emocional do "eu sou" o fundo emocional sobre o qual se pode constituir o descentramento psíquico.

Nestas circunstâncias, o trabalho psicanalítico que tenha como foco o registro das representaçôes, o conhecimento do mundo interno fantasioso, chega muitas vezes a ser desprezado pelo paciente, que busca primariamente por sustentação e espaço humano compartilhados, os quais possam guardar poderes de transformação do campo agônico. Portanto, o holding e o manejo do setting, tal como concebidos por Winnicott, tornam-se os instrumentos primordiais nesta clínica psicanalítica (Vaisberg, 2004).

Para que se possa exercer uma clínica psicanalítica com estas qualidades, compreende-se que a presença real do analista seja elemento fundamental. As oficinas psicoterapêuticas, que trazem a mediação de uma materialidade, revestindo o espaço clínico com o lúdico, garantem a presença real do analista na escolha do objeto do "fazer". Desta maneira, as velas foram escolhidas pela psicanalista e, através do convite ao paciente para que fossem feitas conjuntamente, pôde-se construir um campo clínico, de encontro, capaz de promover a sustentação humana que fecunda o retorno dos sentimentos de unidade e realidade do self.

Pudemos perceber que os pacientes, quando freqüentam a oficina de velas, ainda que no espaço restrito do acontecer clínico, deixam de ser apenas doentes. 
Retornam de um canto isolado de seu ser para ocupar sua totalidade. Acreditamos que esta experiência deixe marcas mutativas em seu viver. É como espaço de descanso do sofrimento infligido pela doença e pela severidade do tratamento que pensamos poder traduzir esta oficina Ser e Fazer.

Tendo em vista o que chamamos de fenômeno clínico de base nesta situação específica, a saber, o potencial para a emergência de um campo agônico, a atuação clínica - nos diversos dispositivos do ambulatório, acolhimento, entrevistas préagendadas, oficinas, discussões clínicas com a equipe - passou a visar intervenções psicoterapêuticas que fossem ao encontro deste fenômeno com o intuito de alívio do sofrimento.

Temos que observar que a criação de oportunidades para que o paciente retome a capacidade de experenciar sua pessoa como una e real, desalojando seu ser do espaço restrito e limitador da doença, acontece apenas se o analista, por sua vez, mantiver-se neste encontro como pessoa una, na plenitude possível de sua presença que, em última instância, é o que garante o movimento de sustentação, de holding. É exatamente neste ponto que começam a surgir questionamentos e reflexóes que dizem respeito aos sentimentos e disposições afetivas do próprio analista quando envolvido neste tipo de clínica. Estamos, portanto, entrando na seara do que, em psicanálise, é conhecido conceitualmente como contratransferência.

Importante que se observe a maneira como Winnicott ([1960] 1983) entende a contratransferência. $O$ autor estende a compreensão deste fenômeno para além do que possa identificá-lo como uma falha do analista, a ser sanada com mais análise. Considera que tal abordagem é inútil, pois encerraria qualquer discussão a seu respeito. Adota a definição de contratransferência como a resposta total do analista às necessidades do paciente. Diz que é sob este prisma que teríamos muito a pensar sobre o uso que o analista pode fazer de suas próprias reações conscientes ou inconscientes diante do impacto que o paciente lhe traz e do efeito deste impacto na atuação profissional.

Conforme citação que abre este texto, Winnicott observa que é de grande valor a permanência da vulnerabilidade do analista diante do impacto causado pelo paciente, ainda que, obviamente, tenha que se manter no papel profissional. Recorda-nos que, por vezes, infelizmente, é assentado em defesas e inibições que o analista conserva sua atitude profissional, o que certamente diminui sua capacidade de sustentar a situação analítica.

Compreende-se, a partir destes esclarecimentos, a importância que nosso autor dá ao reconhecimento, por parte do analista, da qualidade emocional das reações contratransferenciais. A necessidade de tal reconhecimento já fora anunci- 
ada em texto anterior (Winnicott, [1947] 2000) a respeito dos afetos que ganham primazia na relação com o paciente psicótico. Para Winnicott, o analista que trabalha com psicóticos necessariamente se defrontará com a emergência de seu próprio ódio, que tentará invadir a relação. A seu ver não seria possível ao analista manter latentes, ou ignorados, sentimentos contratransferenciais que representarão, em certos momentos, o elemento central da análise. $\mathrm{O}$ autor chamou de "contratransferência objetiva" o conjunto de reações emocionais que determinada situação clínica específica, justificadamente, motiva no analista. Vejamos, a seguir como, em suas palavras, Winnicott concebe a "lida" com os sentimentos evocados pelo processo analítico no próprio analista, ilustrados aqui pelo ódio emergente na relação com o psicótico.

Se for inevitável que ao analista sejam atribuídos sentimentos brutais, é melhor que ele esteja consciente e prevenido, pois lhe será necessário tolerar que o coloquem nesse lugar. Acima de tudo ele não deve negar o ódio que realmente existe dentro de si. O ódio que é legítimo nesse contexto deve ser percebido claramente, e mantido num lugar à parte para ser utilizado numa futura interpretação (Winnicott, [1947] 2000: 279).

A nosso ver, estes apontamentos de Winnicott são inquestionáveis. O reconhecimento e identificação da qualidade dos afetos contratransferenciais na relação com determinado paciente parecem fundamentais para a condução da situação analítica. Somente inteirado de tais afetos, pode o analista permanecer como presença una e real no encontro clínico.

Tomando como verdadeiras as considerações de Winnicott sobre a contratransferência, unidas ao abundante e cotidiano convívio clínico de uma de nós em diversos dispositivos dedicados ao atendimento de pacientes soropositivos, passamos à tentativa de identificação e nomeação dos elementos contratransferenciais de base nesta clínica específica, que é o objetivo do presente estudo.

Encontramos em André Comte-Sponville (1995) algumas indicações que temos adotado como resposta aos nossos questionamentos. São idéias que forjam o início de um caminho para estudos e necessitam de aprofundamento e desenvolvimento. A abordagem dos fenômenos transferenciais em situações clínicas nas quais o sofrimento existencial não pode receber apenas um estatuto psicopatológico, como o sofrer do paciente soropositivo, faz parte do cabedal de demandas muito recentemente direcionado aos psicanalistas, o que exigirá par a passo o desenvolvimento teórico, a articulação com o já construído e o gesto criador por parte do 
profissional, que se dará sempre em um processo coletivo de construção do conhecimento. Sublinhamos, portanto, que este estudo almeja tão somente a comunicação da nomeação de um fenômeno observado em campo transferencial nesta clínica específica. Acreditamos trazer nossa parcela de contribuição adiantando tal comunicação, ainda que nossos estudos ainda se apresentem em curso ${ }^{4}$.

Após tais esclarecimentos, retomamos a questão que se refere à natureza dos elementos contratransferenciais que ganham primazia na clínica da soropositividade. São sentimentos identificados a partir de sua freqüência, predominância e intensidade no próprio ser do analista ou colegas de equipe. São afetos compartilhados, outras vezes negados, outras ainda geradores de grande desconforto emocional diante do qual manobras defensivas são declarada e conscientemente adotadas e, quando inconscientes, podem ser claramente observadas através do olhar treinado do analista.

Narramos a seguir uma situação clínica que evoca sentimentos muito particularmente experimentados no cuidado a soropositivos, não apenas, como já mencionados, experienciados pelo analista, mas estendidos a outros profissionais da equipe. A reunião de condições de extremo desfavorecimento, infortúnio e desamparo do paciente tornam a situação clínica um "caso típico" ${ }^{5}$ que se presta a ilustrar a forma como o analista que trabalha com soropositivos, através do impacto que seu paciente lhe causa, pode se ver assaltado por reações contratransferenciais de características bastante peculiares. Julgamos importante o esclarecimento de que tal narrativa, usada como recurso metodológico, visa comunicar ao leitor a experiência vivida, convidando-o para uma aproximação sensível, da qual poderá emergir com relato próprio.

\section{UM TRISTE ENCONTRO}

A psicanalista conheceu Alex ${ }^{6}$ em seu dia de plantão no acolhimento ${ }^{7}$. Ele chegou com um encaminhamento de um clínico que o enviava de forma bastante abreviada. No receituário constavam apenas duas palavras: moléstias infecciosas. O rapazinho com quem se defrontava a analista era muito jovem e meigo e ela ficou a se perguntar o que o traria ali, pois o médico, de outro serviço, nada esclarecera e não havia nenhum resultado de exame anexo ao encaminhamento, o que costuma ser habitual quando o paciente vem indicado após diagnóstico de soropositividade para o HIV em investigação de clínica médica.

A psicanalista perguntou-lhe em que poderia ajudá-lo e qual era o motivo de seu encaminhamento para um serviço médico de especialidade. Antes, quis saber quantos anos tinha e se estava acompanhado. 
Alex respondeu-lhe que logo completaria 17 anos e que se encontrava sozinho. Costumava ir ao médico com a orientação e conhecimento da mãe, mas esta não o acompanhava, pois tinha um trabalho ao qual não podia faltar. Disse-lhe que há alguns dias uma série de bolhas havia aparecido em suas costas e que a região tornara-se muito dolorosa, tanto antes como depois da erupção. Contou que o médico, generalista, havia lhe explicado que o tratamento para tal problema seria realizado ali, onde agora se encontrava.

A psicanalista pôde compreender, instrumentada por seus treinamentos e atualizações, que a descrição de seus sintomas correspondia a uma suspeita de herpes zoster, reativação do vírus da varicela, por ocasião de episódio de imunodepressão. Este tipo de patologia, de fato, é tratado no ambulatório de moléstias infecciosas, pois o fornecimento de medicação apropriada - bastante cara - encontra-se ali atrelado. Uma outra questão, entretanto, relacionada ao encaminhamento tinha pertinência: qual seria o motivo da falha imunológica do paciente? Afinal o clínico não agira de forma a prescrever a medicação específica que poderia ser apenas autorizada pelo médico infectologista. Teria ele suspeitado de uma infecção pelo HIV? A psicanalista intuiu que o encaminhamento procurava contemplar, além do tratamento do herpes zoster, a investigação sorológica para o HIV.

Conversou um pouco com Alex, perguntou-lhe se alguém da família também havia apresentado aquele problema, como era sua vida, se tinha namoradinha, se já iniciara sua vida sexual, se já havia, por algum motivo, recebido sangue transfundido. Explicou-lhe que não era médica, mas a psicóloga que recebia as pessoas na primeira vez que elas vinham ao serviço e que estas perguntas ajudariam o médico no sentido de entender o porquê de ele estar com aquele problema.

Alex disse-lhe que ninguém em casa havia apresentado o mesmo problema e que havia tido sua primeira relação sexual há 4 meses com uma garota com quem ficara, mas que não dera seguimento à relação. Afirmou ter usado preservativo na ocasião. Nunca havia recebido sangue por transfusão. Sobre sua vida familiar contou-lhe que morava com a mãe e mais cinco irmãos. Não convivia com o pai, de quem a mãe se separara. Ele e o irmão mais velho eram filhos do mesmo pai, enquanto os irmãos mais novos eram filhos(as) cada um(a) de um pai.

A psicanalista pediu-lhe licença e foi conversar com a colega infectologista para passar-lhe o caso. Esta lhe explicou que, caso confirmado o diagnóstico de herpes zoster, talvez não houvesse relação com o HIV, pois muitas vezes até mesmo um grande desfavorecimento emocional pode abalar as condições imunológicas e ocasionar seu aparecimento. Julgou-se que seria melhor não lhe oferecer um teste rápido para o $\mathrm{HIV}$, situação na qual o psicólogo é solicitado a preparar o 
paciente. A médica, no entanto, observou que, apesar de ausência de histórico epidemiológico, não poderíamos descartar a possibilidade de infecção pelo HIV. A prudência exigia a realização da testagem. Combinou-se que o rapaz seria dirigido ao $\mathrm{COAS}^{8}$, onde receberia orientação mais detalhada e a oferta da sorologia HIV em condições que não o impressionariam sobremaneira, pois o enquadramento deste dispositivo carrega consigo nuances pedagógicas. Submetêlo à tensão de um pedido na própria consulta médica poderia assustá-lo desnecessariamente.

Voltando para dar seguimento à entrevista com o rapaz, a psicanalista comunicou-lhe que seria consultado imediatamente pela médica, a qual iria passar-lhe algumas orientações. No final do período da manhã o diagnóstico de herpes zoster estava confirmado, o rapaz medicado e encaminhado para o COAS, onde foi atendido prontamente. Naquela mesma manhã já havia colhido sua sorologia HIV junto a outras que são oferecidas nesta ocasião: hepatite $B$, hepatite $C$ e Sífilis.

Após aproximadamente 15 dias, a psicanalista teve uma lamentável surpresa. A colega que havia atendido Alex no COAS procurou-a para contar que o rapaz apresentava reagência para o HIV. Ela acabara de comunicar-lhe o resultado do exame e o acompanhava preocupada com seu estado emocional: Alex permanecera, aparentemente, sem reação.

A psicanalista viu de longe Alex, recordou-se de seu desamparo e seu próprio coração tornou-se apertado. Desejou imensamente livrar-se da tarefa de realizar a entrevista que daria início a seu tratamento. Na impossibilidade de fazê-lo, preparou-se para colocar em andamento algo semelhante à própria devoção materna especial, compreendida por Granato e Vaisberg (2003) como o desenrolar da preocupação materna primária que se prolonga nos cuidados dirigidos a um filho especial, portador de alguma patologia que ultrapassa o domínio da fantasia, exigindo uma dedicação também especial por parte da mãe, do núcleo familiar e do ambiente. Procurou serenar antes de estar com ele e, quando juntos, não podendo abster-se de cumprir sua tarefa, sem grandes rodeios, disse-lhe que a colega havia lhe informado que, infelizmente, ele não recebera boas notícias. Repetiu-lhe o resultado de sua sorologia. Alex fitou-a com olhar apreensivo, porém, imediatamente, surgiu em seu semblante um ar de resignação. Abaixou a cabeça e manteve-se calado. A psicanalista explicou-lhe que o exame seria repetido, pois só com uma confirmação poder-se-ia dizer que realmente ele tinha tal problema de saúde. Disse-lhe da possibilidade do falso positivo e dos progressos no tratamento da doença, caso esta se confirmasse. Alex mantinha-se calado. Ela não sabia se ele a ouvia, se compreendia suas palavras, porém estas ocupavam um lugar e ela, profundamente, desejava que fossem capazes de levar-lhe algum conforto. 
Perguntou-lhe se gostaria de falar ou esclarecer alguma coisa. Alex quis saber se o tratamento exigiria freqüentemente a presença no ambulatório, pois acabara de arranjar um emprego e não queria faltar muito, pois temia perdê-lo. A inocência contida em sua preocupação tornou-a ainda mais sensível. Explicou-lhe que antes seria necessário confirmar o diagnóstico. Foi então que o rapaz disse que havia algo que precisava contar-lhe. Com um grande esforço para superar o que foi compreendido como sentimento de vergonha, contou-lhe que não duvidava da veracidade do resultado do exame, pois aos 9 anos havia sido "pego" por um grupo de 8 meninos. Em seguida calou-se, não teve coragem de continuar a frase, que foi concluída por ela: você foi agredido sexualmente? Ele apenas fez sinal afirmativo com a cabeça.

A psicanalista sentiu um nó aparecer em sua garganta e uma súbita vontade de chorar, controlada com grande esforço. Suspirou profundamente e olhou para ele tentando expressar compreensão e solidariedade, mas em seu íntimo sofria pelo conhecimento de sua dor e humilhação. Esperou alguns segundos para ver se ele gostaria de falar mais a este respeito e diante de seu silêncio perguntou-lhe como se sentia em relação aos sintomas que o haviam trazido ali. Alex disse que as lesões estavam secas, mas que ainda sentia dor. Ela comunicou-lhe que iria pedir para o médico avaliá-lo e que este também providenciaria novos e mais sofisticados exames.

A analista não conseguia conter sua vontade de chorar. Alex, então, disse que queria lhe fazer uma pergunta. Enquanto fazia este enunciado, simultaneamente, tirou da cabeça um bonezinho que usava e deixou à mostra uma grande área com ausência de cabelos. Perguntou-lhe se poderia indicar-lhe um tratamento para aquele problema com o qual convivia desde bebê. Aos 10 meses, acidentalmente, uma panela de óleo quente entornara sobre sua cabeça, quando se aproximou, furtivamente engatinhando, da mãe que cozinhava. Tendo a mãe se surpreendido, não pôde controlar um movimento brusco que derrubou a panela. Alex não necessitou ficar hospitalizado, porém nunca ganharia cabelos na região da pele lesionada da cabeça.

Aquele relato, enfim, superou qualquer possibilidade da manutenção da tolerância emocional da psicanalista. Ela conseguiu dizer-lhe que o encaminhamento que desejava seria providenciado, pediu-lhe licença a pretexto de pegar alguns papéis que teria que preencher, escondeu-se em um outro consultório qualquer e chorou.

Quando retornou mais compensada e recomposta, comunicou-lhe como havia decidido proceder em termos de sua inserção no ambulatório. Avaliou que talvez fosse melhor para ele ter um médico, homem, que pudesse encarregar-se de 
seu tratamento, possibilitando-lhe o convívio com uma figura masculina que o orientasse, aconselhasse e se preocupasse com ele. Disse-lhe quem seria seu médico e que iria conhecê-lo naquele mesmo dia, para que pudesse avaliar suas dores. Também lhe disse que seria necessário que contasse para sua mãe o que estava ocorrendo e ofereceu-se para fazê-lo na sua presença ou ausência, caso o desejasse. Ele aceitou a oferta e disse que preferia que ela contasse à mãe. Ficaram assim combinados e se despediram, não sem antes ela dizer-lhe que poderia procurá-la quando quisesse. Em seguida dirigiu-se ao consultório do colega infectologista, pessoa acolhedora e afetivamente bastante devotada a seus pacientes, o que justificava sua escolha. Quando começou a contar-lhe o porquê de sua decisão de atribuir-lhe aquele caso, bem como seus detalhes, foi tomada surpreendentemente pela intensidade da reação emocional, parcialmente contida até então, e chorou copiosamente em sua companhia. $\mathrm{O}$ colega sustentou sua pessoa invadida pelo impacto emocional. Disse-lhe que aquilo ocorrera com ele diversas vezes. Retevea ali temporariamente, contando-lhe alguns episódios pelos quais passara. Garantiulhe que veria o rapaz e o tomaria a seus cuidados. Mais tarde, já sozinha, ela ainda verteria muitas lágrimas no banheiro do ambulatório.

\section{NaTUREZA DOS SENTIMENTOS CONTRATRANSFERENCIAIS NA CLÍNICA DA SOROPOSITIVIDADE}

Comte-Sponville (1995) chama de compaixão o sentimento/virtude que acometeu a psicanalista na situação acima compartilhada. Segundo ele, a compaixão, o sofrer "com" pertence, simultaneamente, a estas duas ordens, a dos sentimentos e a das virtudes que seriam definidas como potência, excelência, força que age, poder de humanidade. $\mathrm{O}$ autor nos diz que a virtude é uma disposição para fazer o bem, para se portar bem, e que o bem não se contempla, se faz. Talvez seja melhor não nos alongarmos aqui e apenas computar a intersecção de campos onde se inscreve a compaixão, território dos sentimentos e da ética. É, no entanto, no registro dos sentimentos que a psicanalista testemunha experimentar, por muitas vezes, o compadecimento por seus pacientes. O sofrer "com" brota espontaneamente, recobrindo-se de características contratransferenciais, estabelecendo a forma pela qual a presença do outro afeta o self da analista?.

As origens deste sentimento, indubitavelmente, alojam-se, em parte, em um processo identificatório. Em última instância, portanto, o analista estaria compadecido de si mesmo, imaginando-se vítima do mesmo infortúnio. Não nos parece, entretanto, que esta evidente explicação psicanalítica possa contemplar a amplitude do fenômeno contratransferencial de tal disposição afetiva tão comum 
nesta clínica. Citamos um trecho de Comte-Sponville (1995), com quem compartilhamos opinião em relação a este aspecto da questão:

\begin{abstract}
A piedade não seria mais que um egoísmo projetivo, ou transferencial; na verdade, o que tememos para nós é que nos inspira piedade pelos outros que o padecem, quando compreendemos que poderíamos passar pela mesma provação. Por que não? Mas que diferença faz? A piedade que sentimos não é menos real por causa disso, e, aliás, ela subsiste, notemos de passagem, no caso de males que não poderiam atingir-nos. A morte de uma criança e o sofrimento atroz de seus pais apiedarão igualmente o velho sem filhos. Sentimento absolutamente desinteressado? Não sei, e não me importo. Sentimento real, no entanto, e realmente compadecido. $\mathrm{O}$ resto são as pequenas intrigas do eu, que não valem mais do que valem as intrigas. Seria como querer condenar o amor, ou negar sua existência, a pretexto de que ele estaria sempre ligado a alguma pulsão sexual. Freud, no que concerne ao amor, não era tão bobo assim; por que, no que concerne à compaixão, nós o seríamos? (ComteSponville, 1995: 125).
\end{abstract}

Com esta afirmação, tiramos o compadecimento do analista do campo contratransferencial compreendido como não desejável, do condenável a partir do equívoco de tomar o sofrimento do paciente como uma ameaça imaginária que aponta o mesmo destino para si e que, em sendo "pecado psicanalítico", tem que ser eliminado com mais análise. Preferimos compartilhar com Winnicott ([1947] 2000), quando atribuímos à compaixão na clínica da soropositividade a mesma legitimidade do ódio que o autor reconhece na clínica com psicóticos. Resta, porém, a partir de sua constatação, exatamente, colocar a funcionar todo o esforço analítico, na verdade humano, para lidar com tal experiência, transformando-a em uma das bússolas que possa nos orientar para ir ao encontro do paciente. De posse da plena consciência de nossas reações contratransferenciais, de acordo com os pressupostos éticos declaradamente assumidos pela Ser e Fazer (isto é, o posicionamento a favor de mitigar e aliviar o sofrimento humano), acreditamos ser de grande valia acomodar no ser do analista os sentimentos evocados na relação transferencial. Desta forma poderemos tolerá-los, tomando-os como verdade emocional, experimentada em nós, que nos faz desejar profundamente alterar, na medida das possibilidades, o sofrimento alheio. 


\section{REFERÊNCIAS BIBLIOGRÁFICAS}

Comte-Sponville, A. (1995). A compaixão. Em Pequeno tratado das grandes virtudes (pp.115129). São Paulo: Martins Fontes.

Ferenczi, S. (1928/1992). Elasticidade da técnica psicanalítica. Em Sandor Ferenczi. Psicanálise IV (pp. 25-36). São Paulo: Martins Fontes.

. (1932). Diário clínico. Tradução de Álvaro Cabral. São Paulo: Martins Fontes, 1990.

Granato, T. M. M. \& Vaisberg, T. M. J. A. (2003). Preocupação Materna Especial. Psicologia Clínica, 14 (2), 87-92.

Herrmann, F. (1979). Andaimes do real: o método da psicanálise. São Paulo: Casa do Psicólogo, 2001.

Lévinas, E. (1991). Entre nós: ensaios sobre a alteridade. Petrópolis: Vozes, 2005.

Machado, M. C. L. (1995). Universo em desencanto: conceitos, imagens e fantasias de pacientes psiquiátricos sobre loucura elou doença mental. Tese de Doutorado, Instituto de Psicologia, Universidade de São Paulo, SP.

Mencarelli, V. L. (2003). Em defesa de uma clínica psicanalitica não-convencional: oficinas de velas ornamentais com pacientes soropositivos. Dissertação de Mestrado, Instituto de Psicologia, Universidade de São Paulo, SP.

Mencarelli, V. L. \& Vaisberg, T. M. J. A. (2005). Iluminando o self: uma experiência clínica psicanalítica não convencional. Estudos de Psicologia, 22 (4), 415-423.

Vaisberg, T. M. J. A (2002). Marionetes em consultas terapêuticas: a teoria dos campos na fundamentação de enquadres transicionais. Em Barone, L. M. C. (Org.). O Psicanalista: hoje e amanhã. O II encontro psicanalítico da teoria dos campos (pp. 203-220). São Paulo: Casa do Psicólogo.

Vaisberg, T. M. J. A (2004). Ser e Fazer: interpretação e intervenção na clínica winnicottianna. Em Ser e Fazer: enquadres diferenciados na clínica winnicottiana (pp. 23-58). Aparecida: Idéias e Letras.

Winnicott, D. W. (1947). O ódio na contratransferência. Em Da pediatria à psicanálise (pp. 277-287). Rio de Janeiro: Imago, 2000.

. (1960). Contratransferência. Em O ambiente e os processos de maturação (pp. 145-151). Porto Alegre: Artes Médicas, 1983.

(1962). Objetivos do tratamento psicanalítico. Em O ambiente e os processos de maturação (pp.152-155). Porto Alegre: Artes Médicas, 1983.

- (1963). O medo do colapso. Em Exploraçôes psicanalíticas (pp. 70-75). Porto Alegre: Artes Médicas, 1994.

. (1969). A experiência mãe-bebê de mutualidade. Em Explorações psicanalíticas (pp. 195-202). Porto Alegre: Artes Médicas, 1994. 


\section{NoTAS}

1 Ambulatório de Moléstias Infecciosas e Programa DST/Aids do Município de Santo André.

2 Há momentos precisos do tratamento nos quais é freqüente o surgimento de estados de angústias que variam em intensidade de acordo com a subjetividade de cada um. Tais momentos relacionam-se ao conhecimento do diagnóstico, à revelação do mesmo para os familiares, à introdução da terapia medicamentosa e ao adoecimento por alguma infecção oportunista.

3 Na terminologia utilizada por Winnicott, estes estados agônicos assemelham-se ao que ele veio a chamar de "medo do colapso", de "queda nas agonias impensáveis". Teme-se o retorno a um estado não-integrado, a perda da unidade psicossomática, a perda do senso do real (Winnicott, [1963] 1994).

4 Nossas investigações neste campo de estudos têm nos levado ao encontro das conceituações de mutualidade e da comunicação silenciosa de Winnicott ([1969] 1994) e do tema da empatia na obra de Ferenczi ([1928] 1992). Interessante sublinhar que o último autor, em seu Diário clínico ([1932] 1990), menciona o termo "compaixão" em inúmeras passagens, porém, infelizmente, com pouca precisão conceitual. Incursões na obra filosófica de Lévinas ([1991] 2005), que tem a ética como filosofia primeira, precedendo a metafísica, também têm nos interessado sobremaneira.

5 A expressão "caso típico" foi adotada pela professora Dra. Maria Christina Lousada Machado (1995) em sua tese de doutorado intitulada Universo em desencanto. A autora inspira-se no pensamento de George Lucáks para propor esta terminologia.

${ }_{6}$ Nome fictício dado ao paciente.

7 Este dispositivo tem como finalidade atender necessidades emergenciais do paciente antigo e acolher o novo paciente que se apresenta pela primeira vez no ambulatório para dar início a seu tratamento. A entrevista de acolhimento do caso novo é bastante complexa, pois reúne em um único encontro uma série de finalidades: permitir que o paciente expresse suas angústias; orientá-lo; colocar a funcionar o fluxo de ações para o início do tratamento; acessar informações de caráter epidemiológico para tomar providências em relação aos comunicantes do paciente e notificá-lo junto às autoridades de saúde como cidadão brasileiro portador do HIV para que, desta forma, tenha acesso à medicação e exames que lhe são, de direto, concedidos.

8 COAS: Centro de Aconselhamento Sorológico. É um dispositivo do Programa DST/Aids aberto ao público que deseja espontaneamente realizar a sorologia HIV. Não é necessário nenhum tipo de encaminhamento médico e trata-se de um serviço bastante procurado. Os profissionais que atendem no COAS recebem treinamento específico para realizar a entrevista pré e pós-teste. 
9 Importante comentar que não são todos os pacientes que suscitam esta qualidade de reações contratransferenciais, existindo aqueles que evocam, até mesmo, sentimentos opostos. Portar o HIV ou adoecer de AIDS não concede, apenas por isto, sentimentos de compadecimento aos que com a pessoa convivem no conhecimento de seu diagnóstico. Por outro lado, estes achados clínicos identificados em campo transferencial específico podem levar-nos a refletir a respeito do surgimento de sentimentos contratransferenciais compassivos na clínica psicanalítica de maneira geral.

Recebido em $1^{\circ}$ de abril de 2007 Aceito para publicação em 9 de agosto de 2007 